\title{
A Modified Protocol for Bisulfite Genomic Sequencing of Difficult Samples
}

\author{
Jane J. Pappas, André Toulouse, and W. E. C. Bradley
}

\begin{abstract}
The bisulfite genomic sequencing protocol is a widely used method for analyzing DNA methylation. It relies on the deamination of unmethylated cytosine residues to uracil; however, its high rates of DNA degradation and incomplete cytosine to uracil conversion often lead to failed experiments, uninformative results, and false positives. Here, we report the addition of a single-step multiple restriction enzyme digestion (MRED) designed to differentially digest polymerase chain reaction products amplified from unconverted DNA while leaving those of converted DNA intact. We show that for our model system, RARB2 P2 promoter, use of MRED increased informative sequencings ninefold, and MRED did not alter the clonal representation in one fully methylated cell line, H-596, treated or not with 5-azadeoxycytidine, a methylation inhibitor. We believe that this method may easily be adapted for analyzing other genes and provide guidelines for selecting the most appropriate MRED restriction enzymes.
\end{abstract}

Key words: bisulfite genomic sequencing, multiple restriction enzyme digestion, methylation.

\section{Introduction}

The bisulfite genomic sequencing (BGS) protocol $(1,2)$ is a method of choice for analyzing DNA methylation at the nucleotide level. Sodium bisulfite is used to convert unmethylated cytosine residues to uracil residues in single-stranded DNA. In particular, bisulfite conversion consists of three sequential chemical reactions: sulfonation of cytosine to cytosine-6-sulfonate, deamination to uracil-6-sulfonate, and desulfonation to uracil. However, since 5methylcytosine residues are nonreactive, they remain intact. The

Shulin Li (ed.), Biological Procedures Online, Volume 11, Number 1

(C) to the author(s) 2009

DOI: 10.1007/s12575-009-9010-3 URL: springerprotocols.com; springerlink.com 
bisulfite-converted DNA is then amplified with specific primers designed for converted DNA, and purified polymerase chain reaction (PCR) products, which are usually subcloned, are sequenced.

Bisulfite conversion is so powerful that it has been paired with numerous techniques other than traditional sequencing, including: methylation-specific PCR (3), combined bisulfite restriction enzyme analysis (4), methylation-sensitive single nucleotide primer extension (5), methylation-sensitive single-strand conformation analysis (6), MethyLight (7), oligonucleotide microarray methods (8), denaturing high-performance liquid chromatography with bisulfite genomic sequencing (9), pyrosequencing methylation analysis (10), and methylation-sensitive high-resolution melting-curve analysis (11), among others (see (12) for a review). In addition, many methylation analysis kits are also commercially available.

Unfortunately, high rates of DNA degradation and incomplete conversion reactions often lead to decreased efficiency of the assay. Many attempts have been made to minimize template degradation and/or maximize cytosine conversion (13-19), but overall, the bisulfite conversion protocol has remained unchanged, and no other high resolution or positive display methylation analysis protocol exists. As a result, the BGS protocol, as well as any technique paired with the bisulfite conversion reaction (and, hence, founded on the assumption that conversion is complete) often generate few or no informative results.

In our studies of the RARB2 P2 promoter (20), we found that incomplete conversion was an insurmountable challenge even after modifying the protocol in numerous ways. We, therefore, aimed to circumvent these issues altogether by depleting the PCR populations of products amplified from partially converted or unconverted DNA using a multiple restriction enzyme digestion (MRED) approach. We found that informative sequencings were increased ninefold using it. We believe that this method may easily be adapted for analyzing the detailed methylation status of other genes presenting incomplete cytosine to uracil conversion, and we provide guidelines for selecting the most appropriate restriction enzymes (REs).

\section{Materials and Methods}

\subsection{Cell Culture \\ and Genomic DNA \\ Extraction}

2.1.1. Cell-Line Provenance
Twenty-one cell lines were cultured. CALU-1, SK-MES, CACO2, COLO-201, COLO-205, HCT-15, and LS-180 were 
2.1.2. Cell Culture

2.1.3. Genomic DNA Extraction

\subsection{Bisulfite \\ Conversion}

2.2.1. Bisulfite Conversion obtained from the American Type Culture Collection (Rockville, MD). The CALU-1 daughter cell lines, C-19 and C-59, are $R A R B 2$-transfectants that were established in our laboratory (21). MM-1 was also established in our laboratory (6). NCIH23, NCI-H82, NCI-H125, NCI-H157, NCI-H520, and NCI-H596 were supplied by Dr. Adi Gazdar (NCI, NIH, Bethesda, MD). NBE- $\mathrm{E}_{6} \mathrm{E}_{7}(22)$ was provided by Dr. Jean Viallet (Gemin X Biotechnologies Inc., Montreal, Québec). SW 1222 was given to us by Dr. Clifford Stanners (McGill University, Montreal, Québec). Qu-DB was provided by Dr. Barbara Campling (Queen's University, Kingston, Ontario). T47D, MDA-MB-231 (MB-231), ZR-75B, and HS-578T were kindly provided by Dr. Morag Park (McGill University, Montreal, Québec).

CALU-1, CACO-2, SW-1222, and LS-180 were grown in $\alpha$-MEM medium (Invitrogen, Carlsbad, CA) supplemented with $10 \%$ heat-inactivated fetal calf serum (FCS; Wisent Bioproducts, Saint-Jean-Baptiste de Rouville, Québec). NBE- $\mathrm{E}_{6} \mathrm{E}_{7}$ was grown in keratinocyte-serum free medium (Invitrogen), supplemented with $50 \mu \mathrm{g} / \mathrm{ml}$ bovine pituitary extract, and $5 \mathrm{ng} / \mathrm{ml} \mathrm{recombi-}$ nant human epidermal growth factor (Invitrogen). All other cells were grown in RPMI-1640 medium (Invitrogen) supplemented either with 5\% (SK-MES, NCI-H23, NCI-H125, NCI-H520, Qu-DB, and HS-578T) or 10\% FCS (NCI-H82, NCI-H157, MM-1, T47D, MDA-MB-231, ZR-75B, COLO-201, COLO205, and HCT-15). Where indicated, cells were treated with $1 \mu \mathrm{M} 5$-azadeoxycytidine.

Genomic DNA was extracted using the standard phenol-chloroform technique followed by proteinase $\mathrm{K}$ treatment to ensure complete protein removal (23). DNA was then digested with the PstI RE (New England BioLabs, Ipswich, MA) according to the supplier's directives to shorten the fragment $(2.95 \mathrm{~kb})$ containing the target $R A R B 2 \mathrm{P} 2$ promoter sequence investigated (541 bp; Fig. 1), thereby reducing the possibility for regional double-strand formation (24). PstI was the only RE available for the sequence under analysis.

Multiple DNA samples of each cell line, 1-2 $\mu \mathrm{g}$ each, were treated with bisulfite as per the BGS protocol (1), with minor modifications. Briefly, PstI-digested genomic DNA (1-2 $\mu \mathrm{g})$ was precipitated and resuspended in $25 \mu \mathrm{l}$ distilled water. DNA was denatured with $0.3 \mathrm{~N} \mathrm{NaOH}$ at $37^{\circ} \mathrm{C}$ for $15 \mathrm{~min}$. Fifteen microliters of freshly prepared $10 \mathrm{mM}$ hydroquinone (Sigma-Aldrich Canada Ltd., Oakville, Ontario) was added to the tubes while 
a

$\underset{\text { ggagtggaaaatacataagttataaggaatTTAACAGACAGAAAGGCGC }}{\stackrel{\text { HhaI }}{\longrightarrow}}$

ACAGAGGAATTTAAAGTGTGGGCTGGGGGGCGAGGCGGTGGGCGGGAGGC $\frac{\mathrm{C}}{3}$ HhaI

Alu IDdeI

GAGCGGGCGCAGGCGGAACACCGTTTTCCAAGCTAAGCCGCCGCAAATAA

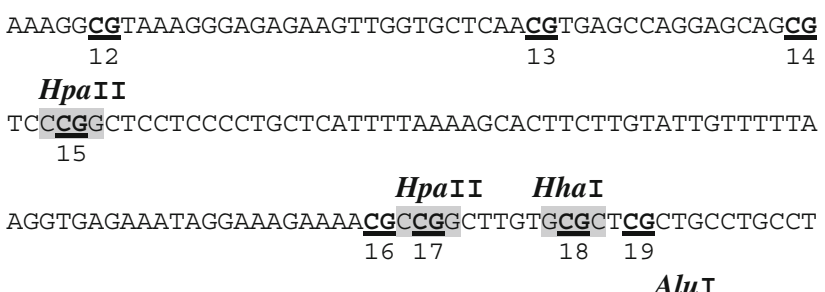

CTCTGGCTGTCTGCTTTTGCAGGGCTGCTGGGAGTTTTTAAGCTCTGTGA

CREB
GAATCCTGGGAGTTGGTGATGTCA
APACTAGTTGGGTCATTTGAAGGTTAG

Ava I

HpaII $\longrightarrow$ RARE $\longrightarrow$ TATA BOX

CAGCCCGGGTAGGGTTCACCGAAAGTTCACTCGCATATATTAGGCAATTC

20

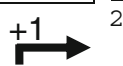

22

Alu I

AATCTTTCATTCTGTGTGACAGAAGTAGTAGGAAGTGAGCTGTTCAGAGG

CAGGAGGGTCTa,ttctttgccaaaggggggaccagaattcCCCCATGCGA JP7

GCTGTTTGAGGACTGGGATGCCGAGAACGCGAGCGATCCGAGCAGGGTTT GTCTGGGCACCGTCGGGGTAGGATCCGGAACGCATTCGGAAGGCTTTTTG CAAGCATTTACTTGGAAGGAGAACTTGGGATCTTTCTGGGAACCCCCCGC CCCGGCTGGATTGGCCGAGCAAGCCTGGAAAATGGTAAATGATCATTTGG ATCAATTACAGGCTTTTAGCTGGCTTGTCTGTCATAATTCATGATTCGGG GCTGGGAAAAAGACCAACAGCCTACGTGCCAAAAAAGGGGCagagtttga tggagttgggtggacttttct

JP6

Fig. 1. RARB2 sequence under analysis. A Unconverted sequence; B converted sequence (all non-CpG-cytosines have been replaced with thymidines). The $541 \mathrm{bp}$ sequence analyzed is comprised between oligonucleotides JP5 and JP7. CG = CpG dinucleotide under investigation ( $n=22) ; \underline{I}=$ non-CpG-cytosine converted to thymidine following bisulfite treatment $(n=82)$; boxes promoter elements; gray-shaded sequences RE sites (please note that these sites are absent in the converted sequence); +1 transcription start site. Direct repeats of the RARE are indicated. The oligonucleotide sequences are underlined and are designed for converted DNA.

at $37^{\circ} \mathrm{C}$, and solutions were carefully mixed by inversion with minimal aeration. Two hundred fifty microliters of freshly prepared 3.6 M sodium bisulfite (Sigma-Aldrich), pH 5.0, was added to the tubes while at $37^{\circ} \mathrm{C}$, and solutions were again carefully mixed by inversion with minimal aeration. Reaction volumes were overlaid with mineral oil and incubated at $55^{\circ} \mathrm{C}$ for $16 \mathrm{~h}$ in the dark. Aqueous phases were transferred to new tubes and desalted 


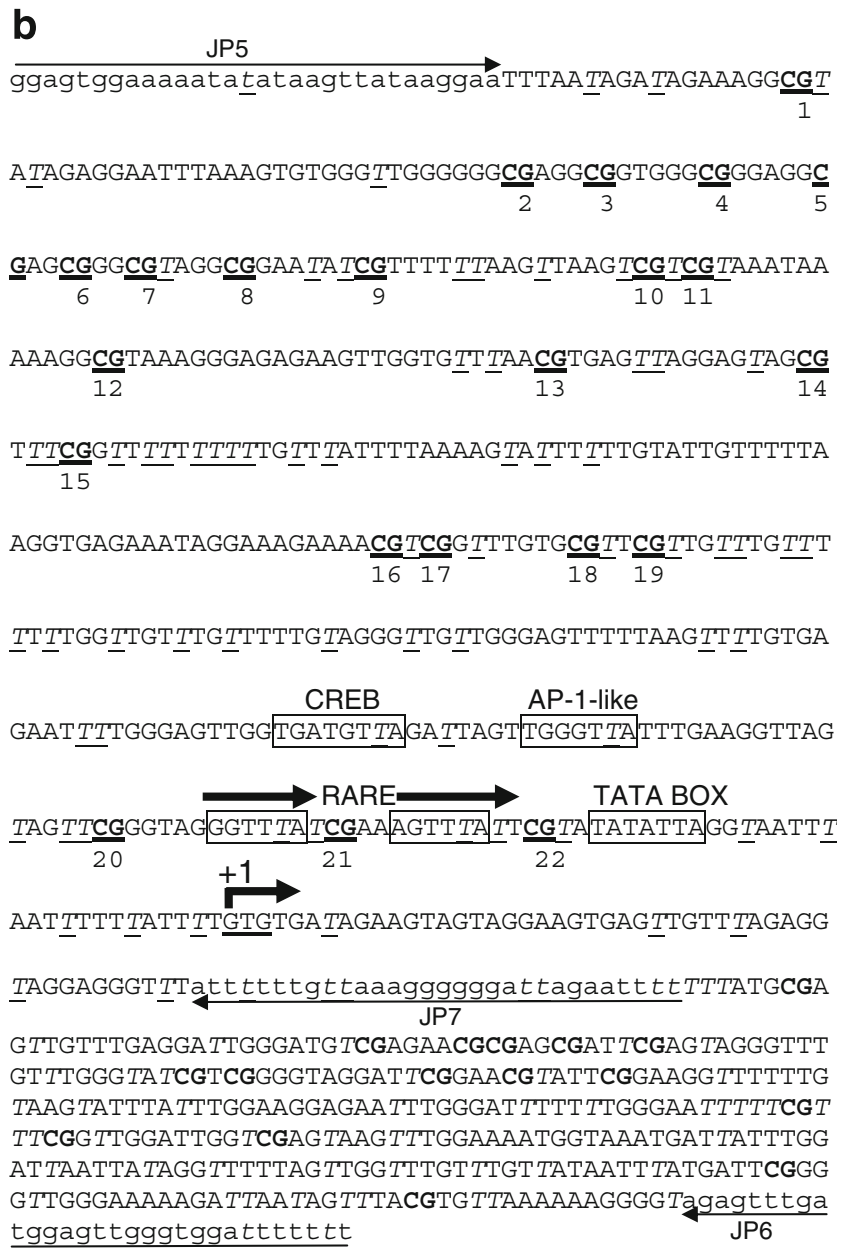

Fig. 1. (continued).

with Wizard Magic Miniprep DNA purification resins (Promega, Madison, WI). DNA was eluted with $120 \mu \mathrm{l}$ distilled water and residual alcohol was removed using speedvac centrifugation. Ten microliters $3 \mathrm{~N} \mathrm{NaOH}$ was added to the remaining $100 \mu \mathrm{l}$ and allowed to incubate for $15 \mathrm{~min}$ at $37^{\circ} \mathrm{C}$. DNA was precipitated with $33 \mu \mathrm{ll} 10 \mathrm{M}$ sodium acetate $\mathrm{pH} 7.8$ and $300 \mu \mathrm{l}$ chilled ethanol using glycogen as a carrier in an ice-water bath for $10 \mathrm{~min}$ and then centrifuged at $13,000 \times g$ for $60 \mathrm{~min}$. The precipitate was resuspended in $100 \mu \mathrm{TE} \mathrm{pH}$ 8.0.

A 541-bp sequence containing $22 \mathrm{CpG}$ dinucleotides (Fig. 1A) was identified within the human RARB P2 promoter (20). PCR amplification consisted of two rounds of amplification: round 1 primers consisted of the upper primer JP5 ( $5^{\prime}$ GGAGTGGAAAAATATATAAGTTATAAGGAA-3') and the lower primer JP6 (5'-AAAAAAATCCACCCAACTCCAT 


\subsection{MRED}

2.3.1. Restriction Enzyme Selection
2.3.2. Special

Considerations
CAAACTCT-3'); round 2 semi-nested primers consisted of JP5 and the lower primer JP7 (5'-AAAATTCTA ATCCCCCCTTTAACAAAAAAT- $\left.3^{\prime}\right)$. Cycling conditions were: $94^{\circ} \mathrm{C} / 4 \mathrm{~min} \times \mathrm{l}$ cycle; $94^{\circ} \mathrm{C} / 1 \mathrm{~min}, 61^{\circ} \mathrm{C} / 2 \mathrm{~min}$, $72^{\circ} \mathrm{C} / 2 \mathrm{~min} \times 5$ cycles; $94^{\circ} \mathrm{C} / 1 \mathrm{~min}, 61^{\circ} \mathrm{C} / 1.5 \mathrm{~min}, 72^{\circ} \mathrm{C} /$ $1.5-2 \mathrm{~min} \times 25$ cycles; $72^{\circ} \mathrm{C} / 5 \mathrm{~min} \times 1$ cycle. Primers were designed following the guidelines found in (25). In particular, they were designed not to contain $\mathrm{CpG}$ dinucleotides so that PCR amplifications were not biased according to methylation status. The minimum number of non-CpG-cytosines available for measuring the rate of cytosine to uracil conversion, for quality control assessment, is 74 . This does not include the one non-CpG-cytosine within the region complementary to JP5 and the seven non-CpG-cytosines within the region complementary to JP7 (see section 2.3.2, Special Considerations).

The original (Fig. 1A) and converted (Fig. 1B) sequences were entered into NEBcutter V.2 at http:/ / tools.neb.com/NEBcutter2/ index.php (New England BioLabs), and RE maps and lists were made. Potential MRED isoschizomers were screened based on the following criteria: (1) RE sites should selectively cut unconverted DNA while leaving converted DNA intact; (2) RE sites may or may not contain CpG-cytosines but should contain at least one non-CpG-cytosine; (3) if RE sites do not contain at least one nonCpG-cytosine, then RE sites should not contain either of the following: (a) a CpG-cytosine, (b) a 3'-C if immediately followed by a G within the downstream sequence, or (c) a $5^{\prime}-\mathrm{G}$ if immediately preceded by a $\mathrm{C}$ within the upstream sequence (for a summary of these criteria, see Table 1).

(1) Since primers can anneal to DNA sequences with less than perfect complementarity and since this may potentially involve primer adenines annealing to unconverted non-CpG-cytosines, we omitted all MRED enzymes with sites within primer sequences.

\section{Table 1}

\section{Guidelines for choosing (MRED) restriction enzymes}

\section{The RE site must contain at least one non-CpG-cytosine}

2 The RE site must be abolished following cytosine to uracil conversion

3 The most $5^{\prime}$ and $3^{\prime}$ nucleotides of the sequence must not form CpG dinucleotides with upstream or downstream sequences respectively

4 The RE site preferably does not have a site within the primer sequences

5 The RE site may be cut with a methylation-sensitive RE, since PCR products are not methylated 
2.3.3. Multiple Restriction Enzyme Digestion

2.4. Gel Extraction and Subcloning
We reasoned that not omiting them might incorporate some incompletely converted molecules. (2) It may be noteworthy to clarify that methylation-sensitive RE may indeed be used since the DNA being cleaved is synthesized in vitro (via PCR) and, hence, not methylated. (3) The five RE we chose (AluI, AvaI, DdeI, HhaI, and HpaII) have a total of 11 sites within the target sequence, and each RE contains one non-CpG-cytosine, except AvaI, which contains two. Since potential causes for lack of single-strandedness (incomplete denaturation, reannealing of complementary strands, or formation of secondary structures between complementary segments within a same strand) can occur anywhere within the entire sequence, we selected a group of enzymes having sites more or less evenly distributed across the entire sequence. RE sites are shown in Fig. 1A, and their characteristics are listed in Table 2. (4) REs with star activity should be avoided. None of the enzymes chosen here have star activity, and conditions that are known to potentially cause star activity in certain REs (including high levels of glycerol or $\mathrm{Mn} 2+$, low or high $\mathrm{pH}$, low or high ionic strength, or presence of DMSO or 2-mercaptoethanol) were also avoided.

Eighty microliters $(\sim 2 \mu \mathrm{g})$ of PCR products were digested with 10-20 units each, AluI, AvaI, DdeI, HhaI, and HpaII (New England BioLabs) as per the supplier's directives for 2.5 to $4 \mathrm{~h}$.

MRED digestions were ethanol precipitated, resuspended in TE buffer $\mathrm{pH} 8.0$, and electrophoresed on 3\% agarose gels. Undigested products (the 541-bp band) were precisely excised using a new scalpel blade and extracted using the Sephaglas ${ }^{\mathrm{TM}}$ BandPrep Kit (GE Healthcare, Uppsala, Sweden). Gel extracted products were subcloned into

\section{Table 2}

\section{Characteristics of the MRED restriction enzymes used for RARB2}

\begin{tabular}{lllll} 
RE & Site & No. of non-CpG-C within RE site & No. of sites within sequence $^{\mathbf{B}}$ & $\mathbf{A}^{* \mathbf{B}}$ \\
\hline AluI & AGCT & 1 & 3 & 3 \\
\hline AvaI & CCCGGG & 2 & 1 & 2 \\
\hline DdeI & CTNAG & 1 & 1 & 1 \\
\hline HhaI & GCGC & 1 & 3 & 3 \\
\hline HpaII & CCGG & 1 & 3 & 3 \\
\hline Total & & & & 12 \\
\hline
\end{tabular}

CpGs are underlined. Bisulfite-convertible cytosines are in boldface. Please note that these cytosines are thymidines in the PCR-amplified product representing bisulfite converted DNA and are therefore not recognized by the RE in question 
2.5. Sequencing

2.5.1. Special

Consideration
pBluescript (Stratagene, La Jolla, CA) or pCR2.1 (Invitrogen, Carlsbad, CA) vectors using T4 DNA ligase (NEB) and transformed into competent DH5 $\alpha$ Escherichia coli cells (Invitrogen).

Plasmid DNA was purified with Qiagen Maxi or Midi kits (Qiagen, Valencia, CA) and sequenced using universal T3 and/or T7 primers. Sequencings were performed in-house or at BioS\&T, Inc., Montreal, Canada.

Each sample was derived from an independent bisulfite-treated DNA sample (i.e., only one bacterial colony was sequenced per bisulfite reaction to ensure that sequencings were not derived from the same PCR DNA template).

\section{Results and Discussion}

In order to compare the efficiencies of the original and the modified protocols, we investigated the rates of conversion of the nonCpG-cytosine residues within the RARB2 P2 promoter region under analysis. These sites are not normally methylated and are, therefore, expected to be fully converted. There are 74 nonCpG-cytosine residues within this region (excluding those found within regions complementary to primers JP5 and JP7): we randomly set the threshold for the status of informativity to $73 / 74$ $(99 \%)$ conversions to uracil and used this threshold to distinguish fully converted sequencings from partially converted ones. In particular, for a sample to be labeled as fully converted, it must have reached $\geq 99 \%$ conversion of these non-CpG-cytosines. Upon comparison, we found that there was a dramatic increase in the number of informative sequencings using our modified protocol: while only $10 \%$ of samples sequenced using the original protocol $(n=200)$ achieved $99 \%$ conversion of non-CpG-cytosines, 91\% of samples sequenced using the modified protocol $(n=176)$ achieved $99 \%$ conversion (Fig. 2). It is interesting to note that the majority of the remaining sequencings using the modified protocol were nearly fully converted (91-98\%). In contrast, nearly all sequencings using the original protocol were nearly fully unconverted $(0 \%$ and $1-10 \%)$.

The use of MRED (using AluI, AvaI, DdeI, HbaI, and HpaII) was shown to prevent methylation bias since both methylated and unmethylated $\mathrm{CpG}$-cytosines were found to be represented at all $22 \mathrm{CpGs}$ in the samples analyzed ( $n=176$; results not shown). In order to determine whether or not there was a bias introduced by the MRED modification, particularly the CpGs 


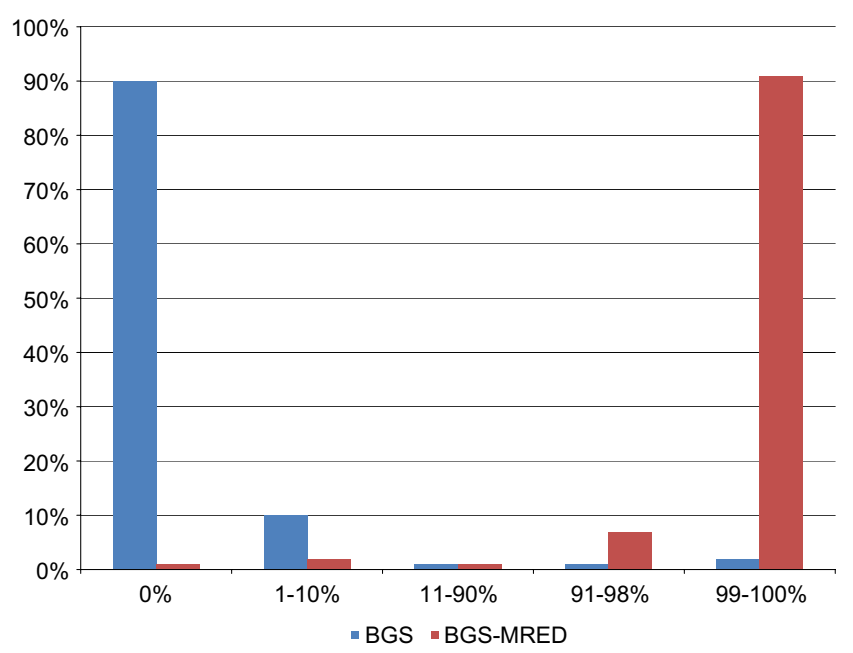

Fig. 2. Rates of nucleotide conversion using the original or the modified protocols. The conversion status of 74 non-CpG-cytosine residues of the RARB2 P2 promoter was analyzed following conversion using the standard BGS protocol (blue bars) or the MRED modification (red bars). Clones were sequenced and grouped according to the percentage of converted cytosine residues. Results show an increase in the frequency of cytosine to uracil conversion using our modified protocol. While only $10 \%$ of samples sequenced using the original protocol $(n=200)$ achieved $99 \%$ conversion of non-CpG-cytosines, $91 \%$ of samples sequenced using the modified protocol $(n=176)$ achieved $99 \%$ conversion. The threshold for the status of informativity was randomly set to $73 / 74$ (99\%) conversions to uracil, and this threshold was used to distinguish fully converted sequencings from partially converted ones.

contained within the $\operatorname{RE}$ sites $(1,7,15,17,18,20$ in Fig. 1), we applied MRED to DNA samples previously analyzed using BGS alone. DNA samples previously extracted from H-596 lung adenosquamous carcinoma cells treated or not with 5-azadeoxycytidine, a methylation inhibitor. Using BGS, they were found to be fully methylated from untreated cells or fully unmethylated following treatment with 5 -azadeoxycytidine (Fig. 3 ). When they were resequenced using the modified protocol, the results were identical: 8/8 sequencings displayed complete methylation (Fig. 3 , top) or complete demethylation (Fig. 3, bottom) at all 20 informative sites. This clearly demonstrates that the introduction of the MRED step does not introduce a bias at any of the 20 informative sites.

Using the BGS protocol ( 1 ) in over 400 sequencings, even with some modifications, we found that incomplete cytosine to uracil conversion and DNA degradation formed insurmountable challenges. In a first effort, numerous attempts to reduce the rate of target DNA degradation were made, including: (1) increasing the amount of genomic DNA from 1 to $10 \mu \mathrm{g}$; (2) decreasing the duration of the bisulfite conversion reaction (15); (3) incorporating up to $5 \mu \mathrm{g}$ salmon sperm DNA; or (4) using agarose beads 


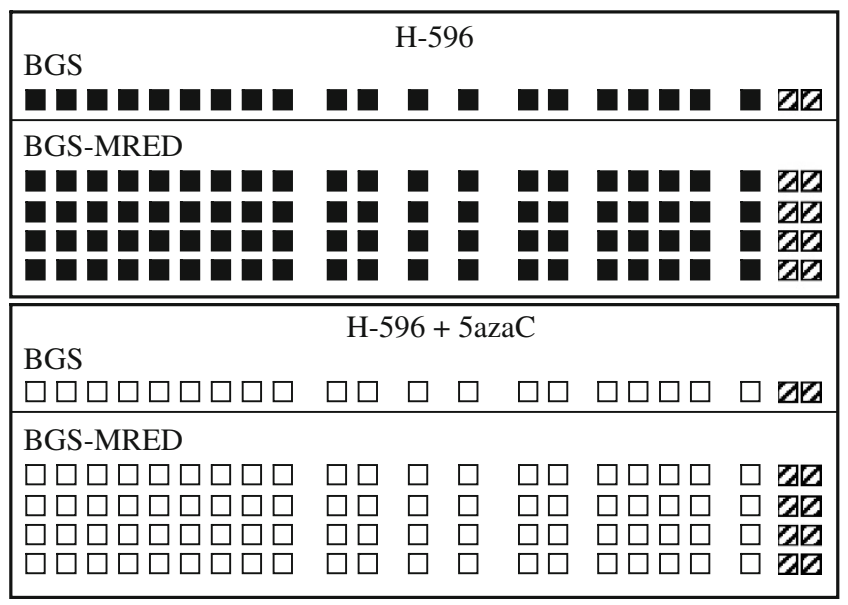

Fig. 3. Schematic representation of the methylation analyses at the 22 $\mathrm{CpG}$ sites within the RARB2 P2 promoter in $\mathrm{H}-596$ cells. Top DNA from untreated $\mathrm{H}-596$ cells; Bottom $\mathrm{H}-596$ cells following 5-azadeoxycytidine treatment (fully demethylated). Each sample was derived from an independently bisulfite-treated DNA sample (only one bacterial colony is sequenced per bisulfite reaction to ensure that sequencings are not derived from the same PCR DNA template). Boxes represent CpG sites. Solid box methylated; empty box not methylated; hatched box status unavailable.

(16). None of these modifications improved the rate of DNA degradation. In addition, the absence of PCR products could not be associated with any one factor (it was variable and unpredictable).

In a second effort, numerous attempts to increase the rate of cytosine to uracil conversion were made, including: (1) digesting the genomic DNA with an endonuclease such as PstI to create smaller fragments containing the target sequence thereby reducing the possibility for regional double strand formation $(24) ;(2)$ denaturing the genomic DNA in an alkaline solution prior to BGS treatment, thereby beginning the BGS protocol with fully denatured DNA; (3) incubating the bisulfite reactions at $95^{\circ} \mathrm{C}$ (24) every $3 \mathrm{~h}$, thereby aiming to maintain complete DNA denaturation; (4) reducing the DNA quantity to as little as $100 \mathrm{ng}$ (13); (5) increasing the sodium bisulfite concentration (6 M) (15), (6) using high-speed BGS (9 M sodium bisulfite for $20 \mathrm{~min}$ at $90^{\circ} \mathrm{C}$ or $40 \mathrm{~min}$ at $\left.70^{\circ} \mathrm{C}\right)(19),(7)$ using a lower incubation temperature, such as $50^{\circ} \mathrm{C}(15)$, to increase the extent of cytosine conversion and/or to reduce the annealing of singlestranded DNA sequences during treatment; (8) monitoring the $\mathrm{pH}$ of the solutions to prevent incomplete desulfonation of pyrimidine residues, which may inhibit DNA polymerases, leading to unsuccessful PCR amplifications (12); (9) changing PCR extension time; (10) annealing temperature; (11) $\mathrm{MgCl}_{2}$ concentration; (12) adding dimethyl sulfoxide to inhibit secondary structure formation (26). In all cases, PCR amplifications were 
once again unpredictable, and when they were productive, none of these modifications increased the rate of occurrence of fully converted samples following BGS above 0-10\%. Different primers were also designed, including fully nested as opposed to seminested primers as was the case here, to no avail.

Such resistance to deamination is a frequent characteristic of RARB2 (unpublished observation, Dr. Michael Trus, Juravinski Cancer Center, Hamilton, Ontario) and is not unique to $R A R B 2$ (e.g., (27-29)). Although high GC content has previously been suggested to cause incomplete conversion (30), the 54l-bp region we targeted has a GC content of $51 \%, 4 \%$ lower than that characterizing most $\mathrm{CpG}$ islands or promoters (31).

$R A R B 2$ DNA methylation has been shown to be correlated with $R A R B 2$ gene inactivation (32-38), and treatment with a methyltransferase inhibitor, 5 -azadeoxycytidine, has been shown to be correlated with demethylation of exonic sequences and reactivation of gene expression $(32,34,37,39)$. However, few studies have analyzed the detailed methylation pattern of the promoter region (33, 40-42), and to our knowledge, studies have not analyzed isolated alleles by sequencing only one subclone per bisulfite conversion reaction (see Section 2.5.1). The vast majority of studies have used methylation-specific PCR, pooling potentially mixed populations of alleles together, as previously described in ref. (38), and not allowing the direct assessment of cytosine to uracil conversion.

To our knowledge, this is the first report of a RE-based method to improve the BGS protocol. This modified protocol is not related to techniques in which $\mathrm{RE}$ digestion is used to reveal and/or quantify DNA methylation-dependent sequence differences in PCR-amplified bisulfite-treated DNA (43) or with techniques in which methylation-dependent retention of preexisting sites, such as BstUI (CGCG; following bisulfite-induced sequence conversion), are exploited to quantify DNA methylation at specific loci, such as in the combined bisulfite restriction analysis (4). These techniques focus on specific CpG sites and are based on the assumption that conversion is complete. In contrast, the present protocol was designed to retain the fine resolution analysis capability of the original BGS protocol. It does so by digesting incompletely converted DNA molecules in the resulting mixed PCR population. Conversion efficiency is not assumed to be $100 \%$ but rather is measured directly for every sample.

We hope that studies requiring fine resolution methylation analyses, such as those investigating the various allelic populations within a cell sample and those in which BGS-associated degradation and inefficient conversion impede research progress, will benefit from using this modified protocol, especially given the growing need for protocols capable of interrogating the methylation status at the nucleotide level (e.g., allele-specific methylation) 
and the growing interest in protocols providing internal quality control parameters. The guidelines for selecting REs are straightforward and may be used for the methylation analysis of any gene. This method requires the addition of only one step, MRED, to the original protocol, adding only 4 h to the 3 -day BGS process. While RE selection may be time consuming for some sequences, the same combination of RE may be used for all subsequent sequencings.

\section{Acknowledgements}

\section{References}

The authors thank Ms. Johane Morin (now at Montreal Diabetes Research Center, CR-CHUM-Technopôle Angus, Montreal, Canada) and Dr. Zhuo Li (Bio S\&T) for their help with sequencings. The authors also thank Dr. Mark Featherstone (School of Biological Sciences, Nanyang Technological University, Singapore) for his critical assessments of and invaluable input to the work in all its phases and Dr. Zeina Saikali (Juravinski Cancer Center, Hamilton, Ontario) for revising the manuscript.

Competing Interests Statement: The authors declare no competing interests.

Funding: This work was supported by grants from the Cancer Research Society. JJP was supported by the McGill University Center for Translational Research in Cancer Fellowship Award, Israel Cancer Research Foundation; the Bourse Fonds Robert Bourassa-Bourse de l'Assemblée Nationale du Québec; the Fondation Marc Bourgie; the Défi Corporatif Canderel; and the Institut du cancer de Montreal.

1. Clark SJ, Harrison J, Paul CL, Frommer M (1994) High sensitivity mapping of methylated cytosines. Nucleic Acids Res 22:29902997

2. Frommer M, McDonald LE, Millar DS, Collis CM, Watt F, Grigg GW, Molloy PL, Paul CL (1992) A genomic sequencing protocol that yields a positive display of 5 -methylcytosine residues in individual DNA strands. Proc Natl Acad Sci U S A 89:1827-1831

3. Herman JG, Graff JR, Myohanen S, Nelkin BD, Baylin SB (1996) Methylation-specific PCR: a novel PCR assay for methylation status of CpG islands. Proc Natl Acad Sci U S A 93:9821-9826

4. Xiong Z, Laird PW (1997) COBRA: a sensitive and quantitative DNA methylation assay. Nucleic Acids Res 25:2532-2534

5. Gonzalgo ML, Jones PA (1997) Rapid quantitation of methylation differences at specific sites using methylation-sensitive single nucleotide primer extension (MsSNuPE). Nucleic Acids Res 25:2529-2531

6. Bianco T, Hussey D, Dobrovic A (1999) Methylation-sensitive, single-strand conformation analysis (MS-SSCA): a rapid method to screen for and analyze methylation. Hum Mutat 14:289-293

7. Eads CA, Danenberg KD, Kawakami K, Saltz LB, Blake C, Shibata D, Danenberg PV, Laird PW (2000) MethyLight: a high-throughput assay to measure DNA methylation. Nucleic Acids Res 28:E32

8. Gitan RS, Shi H, Chen CM, Yan PS, Huang TH (2002) Methylation-specific oligonucleotide microarray: a new potential for high-throughput methylation analysis. Genome Res 12:158-164

9. Couvert P, Poirier K, Carrie A, Chalas C, Jouannet P, Beldjord C, Bienvenu T, Chelly 
J, Kerjean A (2003) DHPLC-based method for DNA methylation analysis of differential methylated regions from imprinted genes. Biotechniques 34:356-362

10. Dupont JM, Tost J, Jammes H, Gut IG (2004) De novo quantitative bisulfite sequencing using the pyrosequencing technology. Anal Biochem 333:119-127

11. Wojdacz TK, Dobrovic A (2007) Methylation-sensitive high resolution melting (MSHRM): a new approach for sensitive and high-throughput assessment of methylation. Nucleic Acids Res 35:e41

12. Fraga MF, Esteller M (2002) DNA methylation: a profile of methods and applications. Biotechniques 33:632-649

13. Feil R, Charlton J, Bird AP, Walter J, Reik W (1994) Methylation analysis on individual chromosomes: improved protocol for bisulfite genomic sequencing. Nucleic Acids Res 22:695-696

14. Tasheva ES, Roufa DJ (1994) Densely methylated DNA islands in mammalian chromosomal replication origins. Mol Cell Biol 14:5636-5644

15. Raizis AM, Schmitt F, Jost JP (1995) A bisulfite method of 5-methylcytosine mapping that minimizes template degradation. Anal Biochem 226:161-166

16. Olek A, Oswald J, Walter J (1996) A modified and improved method for bisulfite based cytosine methylation analysis. Nucleic Acids Res 24:5064-5066

17. Paulin R, Grigg GW, Davey MW, Piper AA (1998) Urea improves efficiency of bisulfite-mediated sequencing of $5^{\prime}$-methylcytosine in genomic DNA. Nucleic Acids Res 26:5009-5010

18. Grunau C, Clark SJ, Rosenthal A (2001) Bisulfite genomic sequencing: systematic investigation of critical experimental parameters. Nucleic Acids Res 29:E65

19. Shiraishi M, Hayatsu H (2004) High-speed conversion of cytosine to uracil in bisulfite genomic sequencing analysis of DNA methylation. DNA Res 11:409-415

20. Shen S, Kruyt FA, den Hertog J, van der Saag PT, Kruijer W (1991) Mouse and human retinoic acid receptor beta 2 promoters: sequence comparison and localization of retinoic acid responsiveness. DNA Seq 2:111-119

21. Houle B, Rochette-Egly C, Bradley WE (1993) Tumor-suppressive effect of the retinoic acid receptor beta in human epidermoid lung cancer cells. Proc Natl Acad Sci U S A 90:985-989
22. Viallet J, Liu C, Emond J, Tsao MS (1994) Characterization of human bronchial epithelial cells immortalized by the E6 and E7 genes of human papillomavirus type 16. Exp Cell Res 212:36-41

23. Warnecke PM, Stirzaker C, Song J, Grunau C, Melki JR, Clark SJ (2002) Identification and resolution of artifacts in bisulfite sequencing. Methods 27:101-107

24. Rein T, Zorbas H, DePamphilis ML (1997) Active mammalian replication origins are associated with a high-density cluster of $\mathrm{mCpG}$ dinucleotides. Mol Cell Biol 17:416-426

25. Lowe T, Sharefkin J, Yang SQ, Dieffenbach CW (1990) A computer program for selection of oligonucleotide primers for polymerase chain reactions. Nucleic Acids Res 18:1757-1761

26. Warnecke PM, Stirzaker C, Melki JR, Millar DS, Paul CL, Clark SJ (1997) Detection and measurement of PCR bias in quantitative methylation analysis of bisulfite-treated DNA. Nucleic Acids Res 25:4422-4426

27. Bearzatto A, Szadkowski M, Macpherson P, Jiricny J, Karran P (2000) Epigenetic regulation of the MGMT and hMSH6 DNA repair genes in cells resistant to methylating agents. Cancer Res 60:3262-3270

28. Boily G, Saikali Z, Sinnett D (2004) Methylation analysis of the glypican 3 gene in embryonal tumours. Br J Cancer 90:1606- 1611

29. Yin H, Blanchard KL (2000) DNA methylation represses the expression of the human erythropoietin gene by two different mechanisms. Blood 95:111-119

30. Shen L, Guo Y, Chen X, Ahmed S, Issa JP (2007) Optimizing annealing temperature overcomes bias in bisulfite PCR methylation analysis. Biotechniques 42:48-52

31. Gardiner-Garden M, Frommer M (1987) $\mathrm{CpG}$ islands in vertebrate genomes. J Mol Biol 196:261-282

32. Bovenzi V, Le NL, Cote S, Sinnett D, Momparler LF, Momparler RL (1999) DNA methylation of retinoic acid receptor beta in breast cancer and possible therapeutic role of 5-aza-2'-deoxycytidine. Anticancer Drugs 10:471-476

33. Bovenzi V, Momparler RL (2000) Quantitation of inhibition of DNA methylation of the retinoic acid receptor beta gene by 5 Aza-2'-deoxycytidine in tumor cells using a single-nucleotide primer extension assay. Anal Biochem 281:55-61

34. Sirchia SM, Ferguson AT, Sironi E, Subramanyan S, Orlandi R, Sukumar S, Sacchi N (2000) Evidence of epigenetic changes 
affecting the chromatin state of the retinoic acid receptor beta 2 promoter in breast cancer cells. Oncogene 19:1556-1563

35. Virmani AK, Rathi A, Zochbauer-Muller S, Sacchi N, Fukuyama Y, Bryant D, Maitra A, Heda S, Fong KM, Thunnissen F et al (2000) Promoter methylation and silencing of the retinoic acid receptor-beta gene in lung carcinomas. J Natl Cancer Inst 92:1303-1307

36. Bovenzi V, Momparler RL (2001) Antineoplastic action of 5-aza-2'-deoxycytidine and histone deacetylase inhibitor and their effect on the expression of retinoic acid receptor beta and estrogen receptor alpha genes in breast carcinoma cells. Cancer Chemother Pharmacol 48:71-76

37. Sirchia SM, Ren M, Pili R, Sironi E, Somenzi G, Ghidoni R, Toma S, Nicolo G, Sacchi N (2002) Endogenous reactivation of the RARbeta2 tumor suppressor gene epigenetically silenced in breast cancer. Cancer Res 62:2455-2461

38. Cote S, Momparler RL (1997) Activation of the retinoic acid receptor beta gene by 5-aza-2'-deoxycytidine in human DLD-1 colon carcinoma cells. Anticancer Drugs 8:56-61
39. Cote S, Sinnett D, Momparler RL (1998) Demethylation by 5 -aza-2'-deoxycytidine of specific 5-methylcytosine sites in the promoter region of the retinoic acid receptor beta gene in human colon carcinoma cells. Anticancer Drugs 9:743-750

40. Arapshian A, Kuppumbatti YS, Mira-y-Lopez R (2000) Methylation of conserved CpG sites neighboring the beta retinoic acid response element may mediate retinoic acid receptor beta gene silencing in $\mathrm{MCF}-7$ breast cancer cells. Oncogene 19:4066-4070

41. Widschwendter M, Berger J, Hermann M, Muller HM, Amberger A, Zeschnigk M, Widschwendter A, Abendstein B, Zeimet AG, Daxenbichler G et al (2000) Methylation and silencing of the retinoic acid receptor-beta 2 gene in breast cancer. J Natl Cancer Inst 92:826-832

42. Pappas JJ, Toulouse A, Hebert J, Fetni F, Bradley WEC (2008) Allelic methylation bias of the RARB2 tumor suppressor gene promoter in cancer. Genes Chromosomes Cancer 47:978-993

43. Sadri R, Hornsby PJ (1996) Rapid analysis of DNA methylation using new restriction enzyme sites created by bisulfite modification. Nucleic Acids Res 24:5058-5059 